\title{
Dermatologic Manifestations as Indicators of Immune Status in HIV/AIDS
}

\author{
Nancy Lutwak, MD and Curt Dill, MD \\ VA New York Harbor Healthcare System, NYU School of Medicine, New York, NY, USA.
}

$\mathrm{J}$ Gen Intern Med 27(7):765

DOI: $10.1007 / \mathrm{s} 11606-012-2062-0$

(c) Society of General Internal Medicine 2012

To the Editors: As Drs. Levy and Jacobson state, dermatological manifestations among patients with HIV may provide insight into their immune status. ${ }^{1}$ Herpes zoster, a common problem, may also be a manifestation of the immune reconstitution inflammatory syndrome (IRIS). ${ }^{2}$

According to a study published in 2005, HIV-positive patients were more likely to develop shingles after six months or less of treatment with effective highly active antiretroviral therapy, after restoration of immunity. ${ }^{3} \mathrm{We}$ reported such a case. ${ }^{2}$

In our patient, when antiretroviral treatment was begun, the patient's viral load (ultrasensitive) was greater than 500,000 copies/ml (75-500,000 ref. range) and the Absolute T4 count was 11 cells per $\mathrm{cmm}$ (ref. range 510-1421). When the patient presented with herpes zoster, his viral load was less than 75 copies per $\mathrm{ml}$ and his absolute T4 count was 296 cells per $\mathrm{cmm}$. The presentation of herpes zoster in our patient was a manifestation of the immune reconstitution inflammatory syndrome (IRIS), which is a result of strengthened immunity. ${ }^{2}$

Of significance, IRIS may be manifested in several ways. It may lead to worsening progressive multifocal leukoencephalopathy, recurrence of cryptococcal disease, worsening of retinitis from cytomegalovirus, shingles, and viral

Published online April 17, 2012 hepatitis . This syndrome usually occurs within 2 months after starting HAART but may occur after years. Younger men are at greatest risk. There is no known clear pathogenesis.

With IRIS, there may be infectious manifestations or problems arising from worsening auto-immune disease, e.g., rheumatoid arthritis. There can be worsening of malignancies, including Kaposi's sarcoma. Patients with IRIS may have fever, lymphadenopathy, respiratory insufficiency, abdominal pain, weight loss or obstructive jaundice. $^{2}$

Work-up may reveal pulmonary infiltrates, pleural effusions, or mediastinal lymphadenopathy on chest $\mathrm{x}$-ray. Antiretroviral therapy should be discontinued in life-threatening situations. $^{2}$

Corresponding Author: Nancy Lutwak, MD; VA New York Harbor Healthcare System, NYU School of Medicine, 423 East 23rd Street, New York, NY 10010, USA (e-mail: Nancy.lutwak@gmail.com).

\section{REFERENCES}

1. Levy TH, Jacobson DF. Dermatological Manifestations as Indicators of Immune Status in HIV/AIDS. J Gen Intern Med. 2012;27(1):124.

2. Lutwak N, Dill C. HIV+Patient with Herpes Zoster: Manifestation of the Immune Reconstitution Inflammatory Syndrome. Am J Emerg Med. 2012;30(1):254.e3-5. Epub 2010 Dec 3.

3. Sarazin E, Nacher M, Toure Y, Clyti E, et al. Dermatological manifestations associated with immune reconstitution syndrome in HIV+patients starting HAART: a retrospective study in French Guiana. Bull Soc Pathol Exot. 2005;98(3): 187-192. 